\title{
ADHD in school children and educators' perceptions
}

\author{
Lavinia Maria HOGEA ${ }^{1}$, Mihaela AUNGURENCE ${ }^{2}$, Teodora ANGHEL ${ }^{1}$ \\ ${ }^{1}$ Neuroscience Department, "Victor Babes" University of Medicine and Pharmacy, Timisoara, Romania \\ ${ }^{2}$ Psychologist, Psychotherapist
}

\begin{abstract}
Objective. To involve the teachers in early identification of ADHD symptoms in school age. To highlight some aspects of ADHD diagnostic.

Method. We analyzed the situation of the children with a medical diagnostic with specific treatment (stimulant or non-stimulant) for ADHD in Timis County. 53 teachers from Timis County filled in the Disruptive Behavior Disorders Rating Scale (DBDRS) - teach form, made by Barkley R.A for identification the ADHD symptoms in children from their schools.

Results. All the teachers perceived that a lot of children have disruptive behavior in various school situations; the frequency of ADHD symptoms with clinical signification was comparable with the medical diagnostic of ADHD. The conclusion of the paper was that the teachers could have an important role in early diagnostic and treatment of $A D H D$.
\end{abstract}

Keywords: ADHD, school, teacher

\section{INTRODUCTION}

ADHD is a common condition in children-psychiatrists offices, its frequency increasing from year to year, with more than half remaining undiagnosed. The boys-girls ratio is $2.5-12: 1$, at boys in the predominant school age and at girls is constant by age groups. The type of ADHD prevailed with inattention is $10-15 \%$, the one with hyperactivity $5 \%$ and the combined one makes $80 \%$ of all cases. ADHD is characterized by early onset before age 7 , by a combination of hyperactivity, disorderly behavior and inattention (lack of attention). The duration of the disorder must be at least 6 months, and the symptoms are grouped in the inattention and hyperactivity ones/impulsivity.

The ADHD diagnosis is influenced by numerous factors: child characteristics, family, school, socio-economic status.
In a study performed by Sax and Kautz (2003) it is shown that $52.4 \%$ of cases diagnosed with ADHD are suggested by teachers (or anyone from school staff), $30.2 \%$ were suggested by parents and only $14.4 \%$ suggested by the doctor, child psychiatrist or psychologist.

The present study was focused on involving teachers in early detection of ADHD symptoms to school-aged children, as well as highlighting some aspects of medical diagnosis of ADHD.

\section{MATERIAL AND METHOD}

There were taken out 635 children aged 6-18 of which 216 were diagnosed with ADHD and are in treatment (stimulant or non-stimulant) in Timis County; and 53 teachers (secondary school professors and teachers) from 3 schools in Timis County. 
The used tests are: Rating Scale Disruptive behavior disorders - version for educators, the scale that allows the identification of ADHD symptom and TOP (DBDRS) $(1,2)$; The questionnaire for school situations assessment.

\section{RESULTS}

The analysis of the correlation between a child's background and gender by the Pearson correlation coefficient is statistically significant ( $p<0.01)$. The correlation between the number and severity of children problems in most school situations and the frequency of ADHD and/or TOP symptoms with clinical significance is also statistically significant (Fig. 1).

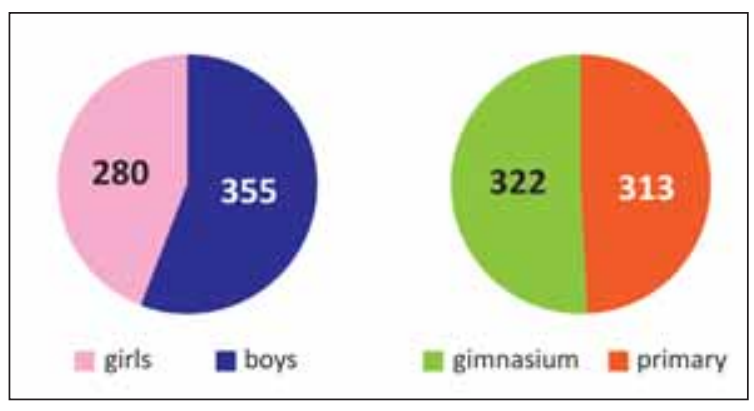

FIGURE 1. Children assessed by teachers

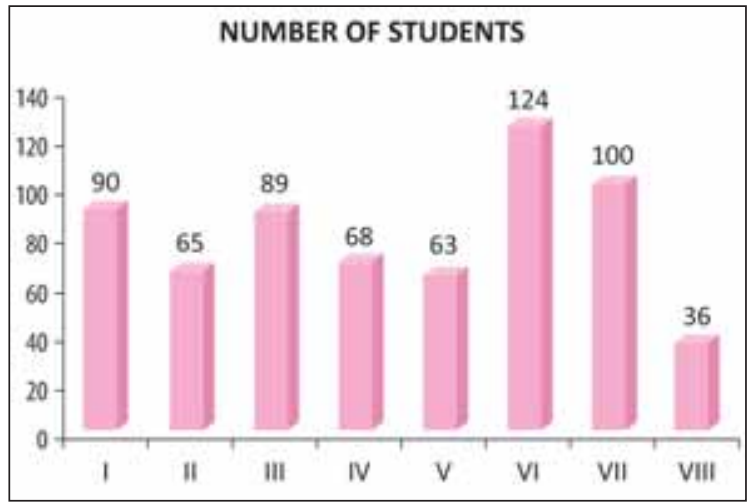

FIGURE 2. Distribution of children assessed by teachers according to class

TABLE 1. Situations at school

\begin{tabular}{|l|l|}
\hline 1 & When you get to school \\
\hline 2 & During individual bank ac vi es \\
\hline 3 & During small group ac vi es \\
\hline 4 & During the game open class \\
\hline 5 & While teaching in class \\
\hline 6 & In break \\
\hline 7 & At lunch \\
\hline 8 & Corridor \\
\hline 9 & In the bathroom \\
\hline 10 & In excursions \\
\hline 11 & In special mee ngs \\
\hline 12 & By bus \\
\hline
\end{tabular}

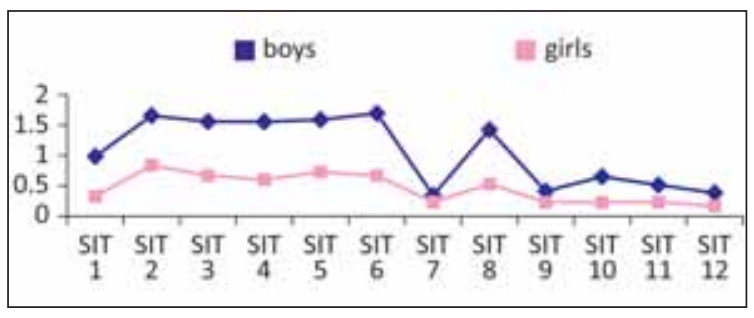

FIGURE 3. Distribution of children according to sex in different school situations

SIT 2 - individual bank activities, SIT 6 - break and SIT 8 - corridors are statistically significant.

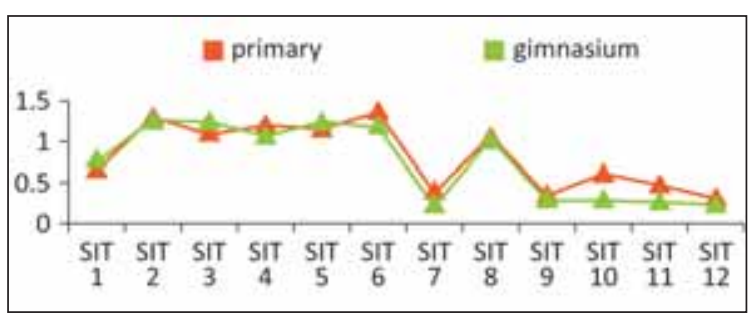

FIGURE 4. Distribution of children according to years of study on the different school situations

SIT 2 - individual bank activities, SIT 6 - break SIT 8 - corridors and SIT 10 - trips are statistically significant.

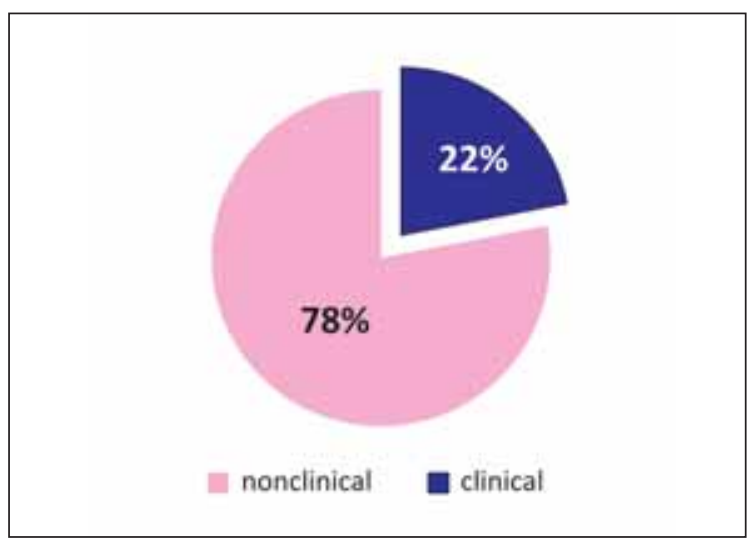

FIGURE 5. Frequency of clinically significant ADHD symptoms

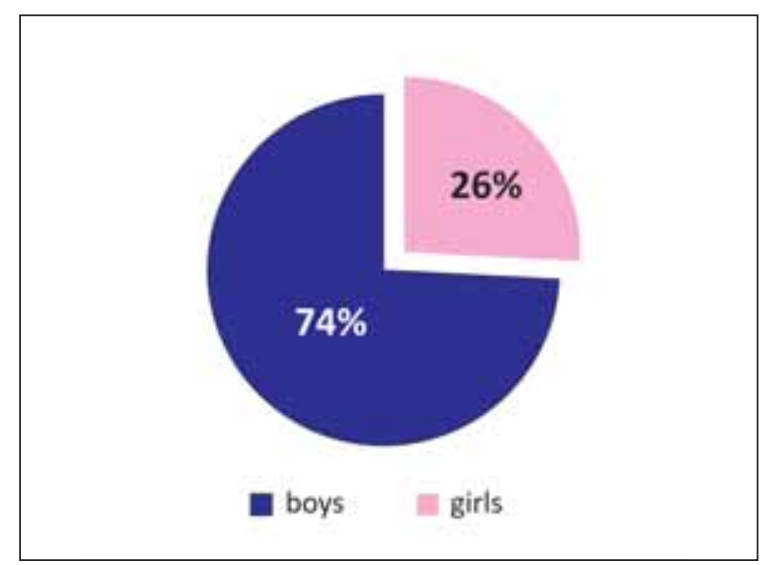

FIGURE 6. Frequency of clinically significant ADHD symptoms (gender distribution) 


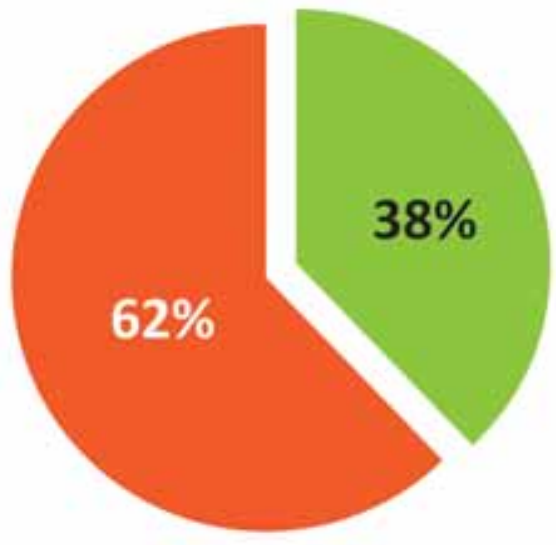

primary gimnasium

FIGURE 7. Frequency of clinically significant ADHD symptoms (school cycle)

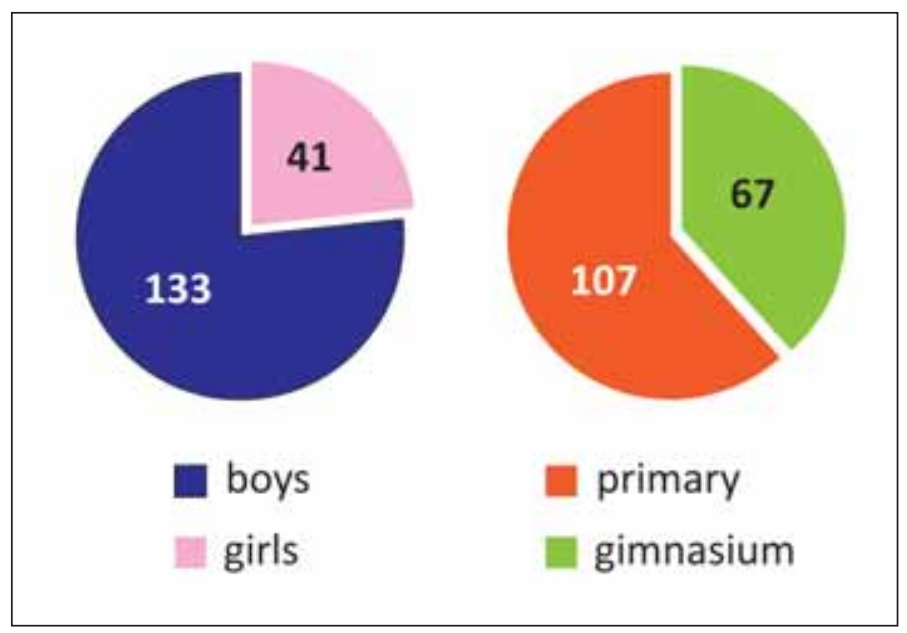

FIGURE 8. School Children diagnosed and under treatment. Total - 174

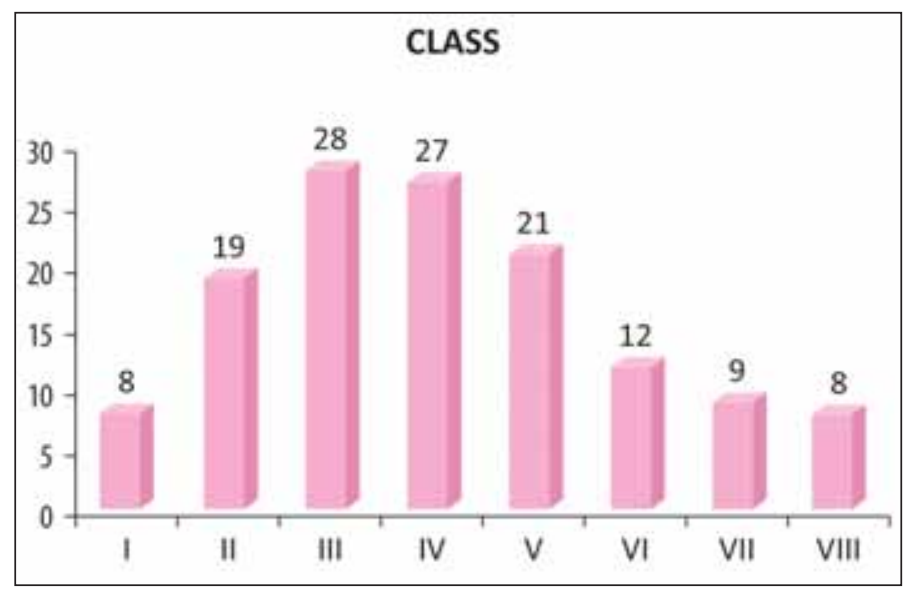

FIGURE 9. Frequency of clinically significant ADHD symptoms (class)

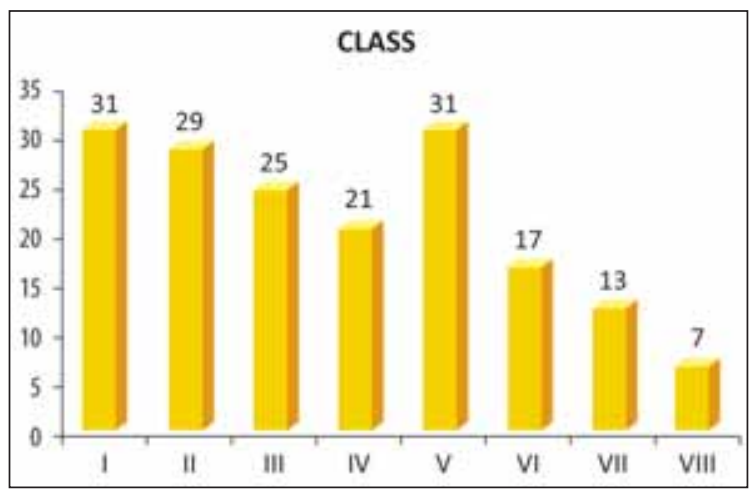

FIGURE 10. Copii şcolari diagnosticați şi aflați în tratament (pe clase)

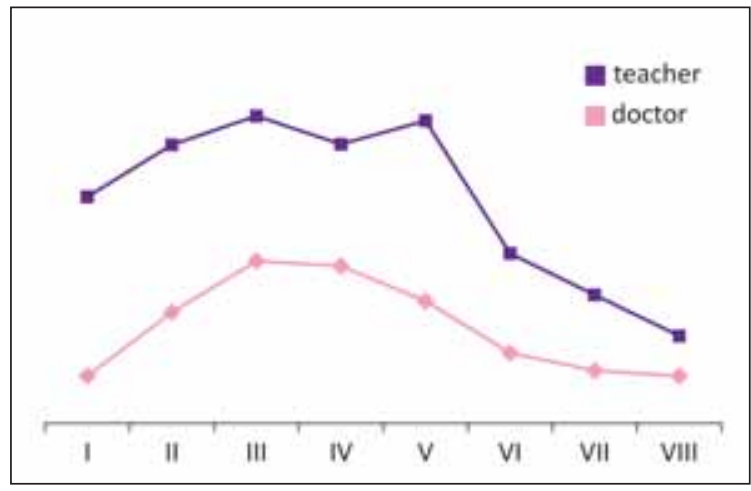

FIGURE 11. Distribution of people involved in evaluation

\section{CONCLUSIONS}

Regardless of origin, gender or school cycle, teachers perceive that many children are manifesting non-compliant behavior in various situations at school, which may have clinical significance for ADHD and/or oppositionist disorder. The symptoms with clinical significance for ADHD and/or TOP are more common in boys and in primary school.

The results obtained from assessments by teachers/professors are comparable to those derived from medical evaluations of children. Educators (professors or teachers) can be in many cases, the first to suggest ADHD diagnosis, the increasing pressure on children regarding the obtaining of academic performance since kindergarten may be related to this.

A large percentage of children "diagnosed" with ADHD by teachers suggest that they can sometimes confuse ADHD symptoms with other problems such as anxiety, various stressful life situations, Low IQ.

Even if educators or others within the school often suggest the diagnosis of ADHD, few studies provide data about the school's role in identifying the characteristic symptoms of ADHD. 


\section{REFERENCES}

1. Friedman-Weieneth, J.L.; Doctoroff, G.L.; Harvey, E.A.; Goldstein, L.H. The Disruptive Behavior Rating Scale-Parent Version (DBRS-PV): Factor analytic structure and validity among young preschool children. Journal of Attention Disorders. 2009, 13 (1): 42-55.

2. Barkley R.A. Copilul dificil - Manualul terapeutului pentru evaluare şi pentru trainingul părintilor, Editura ASCR,

Cluj-Napoca, 2009, ISBN: 978-973-797364-1.
3. Jurma A.M., Hogea L.M., Motoc A.G.M. Mental health symptoms in siblings of children with Attention Deficit/Hyperactivity Disorder and Autism Spectrum Disorder, European International Journal of Science and Technology, Timisoara 2015, ISSN: 2304-9693.

4. Scahill, L.; Schwab-Stone, M. Epidemiology of ADHD in school-age children. Child and Adolescent Psychiatric Clinics of North America, Vol 9(3), Jul 2000, 541-555.
5. Eiraldi, R.B, Power T.J., Nezu C.M. Patterns of Comorbidity Associated With Subtypes of Attention-Deficit/Hyperactivity Disorder Among 6 - to 12-Year-Old Children. Journal of the American Academy of Child \& Adolescent Psychiatry, 1997, Volume 36, Issue 4, Pages 503-514.

Conflict of interest: none declared Financial support: none declared 